\title{
Ensinar saúde/enfermagem numa nova proposta de reestruturação acadêmica
}

\author{
HEALTH/NURSING TEACHING INANEW PROPOSAL OF ACADEMIC RESTRUCTURATION \\ ENSEÑAR SALUD/ENFERMERÍA EN EL NUEVA PROPUESTA \\ DE REESTRUCTURACIÓNACADÉMICA

\section{Josicélia Dumêt Fernandes', Naomar de Almeida Filho², Darci de Oliveira Santa Rosa ${ }^{3}$, Márcia Pontes ${ }^{4}$, Neuranides Santana ${ }^{5}$}

\author{
1 Professora Titular da \\ Escola de Enferma- \\ gem da UFBA. Dou- \\ tora em Enfermagem. \\ Vice-líder do Grupo \\ de Estudos e Pes- \\ quisas em Educação, \\ Etica e Exercício de \\ Enfermagem. Pesqui- \\ sadora do CNPq. \\ dumet@ufba.br \\ 2 PhD em Epidemio- \\ logia. Professor \\ Titular do Instituto de \\ Saúde Coletiva, \\ Universidade Federal \\ da Bahia (UFBA). \\ Pesquisador do CNPq. \\ Reitor da UFBA. Sal- \\ vador, BA, Brasil. \\ 3 Doutora em Enferma- \\ gem. Professora \\ Adjunta da Escola de \\ Enfermagem, Univer- \\ sidade Federal da \\ Bahia (UFBA). Líder \\ do Grupo de Estudos \\ e Pesquisas em Edu- \\ cação, Ética e Exer- \\ cício de Enfermagem. \\ Salvador, BA, Brasil. \\ 4 Mestre em Educação. \\ Professora Adjunta \\ da Faculdade de \\ Educação, Universi- \\ dade Federal da \\ Bahia (UFBA). \\ Salvador, BA, Brasil. \\ 5 Mestra em Enferma- \\ gem. Doutoranda da \\ Escola de Enferma- \\ gem, Universidade \\ Federal da Bahia \\ (UFBA). Salvador, \\ BA, Brasil.
}

\begin{abstract}
This study has as objective the presentation of a proposal of curricular restructure, evaluating its influence in the health instruction, focusing the nursing school. It presents, initially, the real panorama of superior education in Brazil. After that, it shows one curricular restructure proposal. Finally, it approaches the nursing/health teaching configuration in this proposal. This study points to the need of construction of a regenerated university, in its interface with the health graduation. It supports the development of educative practices adherent to the life context and to the plurality and singularity of the real social processes.
\end{abstract}

\section{KEY WORDS}

Education, nursing.

Curriculum.

Teaching.

\section{RESUMEN}

El estudio tiene como objetivo presentar una propuesta de reestructuración de la arquitectura curricular, evaluando sus objetivos en lo que consiste al enseño en salud, con foco en la enfermería. Para alcanzar ese objetivo, se presenta, inicialmente, el panorama actual de la educación superior en Brasil. Después, se muestra una proposición de reestructuración curricular. Finalmente, se trabaja la configuración del enseño en la salud/enfermería, frente a esa propuesta. El estudio apunta para la necesidad de construcción de una universidad más actualizada, en su articulación con la formación en el área de la salud, favoreciendo el desarrollo de prácticas educativas más sólidas a los contextos de la vida y a la pluralidad y singularidad de los procesos sociales concretos.

\section{DESCRIPTORES}

Educación en enfermería.

Currículum.

Enseñanza. 


\section{INTRODUÇÃO}

O mundo globalizado e seus desdobramentos políticos, econômicos e sociais apontam a necessidade de transformações em todos os setores das sociedades. No setor da Educação e, particularmente, na Educação Superior, urge enfrentar os desafios impostos pelas transformações de saberes, em conjunturas cada vez mais complexas. Na superação desses desafios, as Instituições de Ensino Superior produzem conhecimentos novos e adequados aos contextos globalizados emergentes, além de implementarem processos formativos de indivíduos com compromisso ético, estético e político de afirmação da vida, capazes de articular saberes e práticas de modo contextualizado, visando a compreender e intervir na realidade cambiante da sociedade contemporânea. Nesse panorama, a universidade brasileira precisa de uma reforma profunda e verdadeira, que a qualifique para enfrentar altivamente processos, em curso, de transnacionalização do mundo ${ }^{(1)}$.

Temos, portanto, como desafio, construir uma universidade socialmente comprometida, academicamente competente e pedagogicamente inovadora, superando velhos recortes disciplinares com programas de formação de graduação e pós-graduação cada vez mais abrangentes e inter-disciplinares, articulados em uma arquitetura acadêmica renovada ${ }^{(2)}$.

Como resposta a tão importante desafio, o presente texto tem como objetivo apresentar a proposta de reestruturação da arquitetura curricular da Universidade Federal da Bahia (UFBA), avaliando seus desdobramentos no que tange ao ensino em saúde, com foco na Enfermagem.

Para o alcance desse objetivo, apresenta-se, inicialmente, o panorama atual da educação superior no Brasil; em seguida, explicita-se uma proposição de reestruturação curricular e, finalmente, aborda-se a configuração do ensino na saúde/enfermagem frente a essa proposta.

Espera-se, dessa maneira, contribuir para a construção de uma universidade renovada em sua interface com a formação na área da saúde, favorecendo o desenvolvimento de práticas educativas mais aderentes aos contextos da vida e à pluralidade e à singularidade dos processos sociais concretos.

\section{ARQUITETURA CURRICULAR DA EDUCAÇÃO SUPERIOR NO BRASIL}

A atual arquitetura curricular da educação superior no Brasil configura-se em uma concepção fragmentada do conhecimento, alienada da complexidade dos problemas da natureza, da sociedade, da história e da subjetividade; modelos de formação superados em seus contextos de origem; reformas universitárias impostas pelos governos militares nas décadas de 1960-1970; abertura de mercado e desregulamentação da educação superior nos anos 1980-1990, dentre outros ${ }^{(2)}$.

Essa configuração caracteriza-se por múltiplas titulações, tais como licenciaturas, bacharelado, habilitação, tecnólogo, especialização, mestrado (acadêmico e profissional), doutorado.

A arquitetura acadêmica vigente no país reveste-se, pois, de: precocidade na escolha da carreira profissional; processo seletivo limitado, pontual e traumático para o ingresso na graduação; elitização da educação universitária; viés monodisciplinar na graduação; dicotomia dos diversos níveis de ensino; ensino orientado para a formação profissional com reduzido incentivo à plena formação cidadã, artística e científica ${ }^{(2)}$.

Acrescenta-se a isto o fato de que princípios contemporâneos da formação universitária, como a flexibilidade e a inter-disciplinaridade, são praticados por um número muito reduzido de cursos de graduação. Na maioria dos cursos, as práticas pedagógicas são tradicionais, com predominância de aulas expositivas e uso incipiente de recursos tecnológicos e outras formas inovadoras de ensino. A estrutura organizacional das unidades de ensino indica falta de articulação entre Colegiados, Departamentos e Núcleos de Pesquisa e Extensão ${ }^{(2)}$.

$\mathrm{Na}$ área da saúde, o processo formativo tem indicado pouca capacidade para dar conta do amplo espectro de demandas apresentadas nas situações de adoecimento ou sofrimento por problemas de saúde, indicando a necessidade fundamental das práticas interdisciplinares e multiprofissionais ${ }^{(3)}$.

O ensino de graduação na área da saúde, tal como exercido na grande maioria das instituições, tem apresentado poucos indicativos de uma orientação integradora entre ensino, trabalho e cidadania. Tal lacuna demanda a necessidade de uma formação teórico-conceitual e metodológica que potencialize competências para a integralidade, onde se incluem atenção às necessidades de saúde da população e desenvolvimento do sistema de saúde ${ }^{(4)}$.

Essa realidade revela o esgotamento do modelo de ensino de graduação vigente no país, tendo por conseqüência: campos do saber estreitos, contemplados nos projetos pedagógicos, precocidade na escolha das carreiras, altos índices de evasão de alunos por desencanto com os estudos e por falta de condições de permanência, descompasso entre a rigidez da formação profissional e as amplas e diversificadas competências demandadas pelo mundo trabalho e, sobretudo, os desafios da Sociedade do Conhecimento ${ }^{(2)}$. 
Para superação dessa realidade, tem sido consenso entre os estudiosos $^{(1,5-6)}$ da educação superior a premência de modelos de formação mais abrangentes, flexíveis e integradores.

\section{UMA PROPOSTA DE SUPERAÇÃO(a)}

Frente ao atual panorama da educação superior no Brasil, a UFBA considera a necessidade de construir um tipo diferente e renovado de instituição universitária que possibilite a internacionalização da educação superior, direcionada para o desenvolvimento com justiça e bem estar social. Nesse direcionamento, busca-se implementar uma arquitetura acadêmica, com formação básica interdisciplinar, integrando a graduação e a pós-graduação, possibilitando condições para a pesquisa com qualidade, além da valorização da extensão universitária, por meio de um modelo próprio ajustado à diversidade brasileira, reduzindo as barreiras entre a graduação e a pós-graduação.

Trata-se de uma proposta de renovação do ensino de graduação por meio de projetos acadêmico-pedagógicos criativos e consistentes, com temas relevantes da cultura contemporânea, dotando a educação superior de maior mobilidade, flexibilidade, eficiência e qualidade, visando à compatibilização com demandas e modelos de educação superior do mundo contemporâneo.

Essa proposta, denominada Universidade Nova (UN), objetiva a reestruturação do modelo acadêmico atualmente vigente, em rede ou em articulação com outras universidades públicas brasileiras, implementando uma nova arquitetura curricular. Para o alcance desse objetivo, propõe-se implantar uma arquitetura curricular modular, com vistas à diversificação dos modelos de formação profissional e acadêmica, através do Bacharelado Interdisciplinar (BI), sem perder de vista as atividades de pesquisa e extensão e o fortalecimento da integração da graduação com a pós-graduação. Vale salientar, também, a adoção de novas modalidades de processo seletivo pautadas por maior diversificação e maior flexibilidade de instrumentos e procedimentos, para ampliar a inclusão social pela educação superior.

Pretende-se a implantação de um regime de três ciclos de educação superior: o primeiro propicia a formação geral e é pré-requisito para os ciclos seguintes; o segundo consiste na formação profissional em carreiras específicas e o terceiro está voltado para a formação acadêmica científica, artística e profissional, em nível de pós-graduação.

A introdução do regime de ciclos, além de implicar o ajuste da estrutura curricular dos cursos de formação profissional e de pós-graduação, propõe a incorporação de no-

(a) A apresentação dessa proposta está baseada no documento, de autoria da equipe técnica da Pró-Reitoria de Graduação da UFBA, denominado Plano de reestruturação da arquitetura curricular da Universidade Federal da Bahia, versão 3.1 de 30/07/2007. vas modalidades de processo seletivo, tanto para o BI, como para as opções de prosseguimento da formação posterior.

O BI compreende uma nova modalidade de curso de graduação que se caracteriza por agregar formação geral humanística, científica e artística a um aprofundamento num dado campo do saber, constituindo a etapa inicial dos estudos superiores. Tem como objetivo promover o desenvolvimento de competências e habilidades que possibilitarão ao egresso a aquisição de ferramentas cognitivas que conferem autonomia para a aprendizagem ao longo da vida, bem como uma inserção mais plena na vida social, em todas as suas dimensões.

O egresso do BI deverá ser capaz de realizar uma leitura pertinente, sensível e crítica da realidade humana em que está inserido. Além disso, poderá enfrentar as exigências do mundo do trabalho no desempenho de ocupações diversas que mobilizem, de modo flexível, conhecimentos, competências e habilidades gerais e específicas.

O BI apresenta-se em quatro modalidades de oferta, abrangendo grandes áreas do conhecimento: Artes, Humanidades, Ciências e Tecnologias, Ciências da Saúde. Sua estrutura curricular está configurada por duas etapas de formação, estruturadas em eixos, que se distinguem quanto à função que exercerão na formação acadêmica dos alunos. A primeira etapa é a de Formação Geral, destinada à aquisição de competências e habilidades que permitam a compreensão pertinente e crítica da realidade natural, social e cultural. A segunda é a de Formação Específica, destinada a proporcionar aquisição de competências e habilidades que possibilitem o aprofundamento num dado campo do saber teórico ou teórico-prático, profissional disciplinar, multidisciplinar ou interdisciplinar.

Concluídos essas etapas, o egresso recebe um diploma de Bacharel em área geral de conhecimento (Artes, Humanidades, Ciências) que poderá lhe conceder flexibilidade no acesso ao mundo do trabalho. Caso o egresso deseje prosseguir seus estudos, poderá optar por licenciaturas, bacharelados em campo específico, cursos profissionais ou o mestrado acadêmico.

O desenvolvimento das ações previstas nessa proposta fundamenta-se nos seguintes princípios norteadores: ampliação do acesso e maior eficácia nos processos de ensino, de modo a aumentar a relação professor/aluno; democratização do acesso; adequação e atualização das estruturas de apoio às atividades-fim, de modo a atender aos novos modelos acadêmicos a serem implantados; inovação pedagógica com incentivo e apoio a práticas pedagógicas inovadoras e mais compatíveis com as características cognitivas de indivíduos em uma sociedade de base tecnológica; excelência acadêmica e responsabilidade social, de modo a garantir o compromisso com a qualidade acadêmica e a busca da superação das carências da sociedade brasileira. 
No atendimento a esses princípios, as unidades de ensino apresentarão suas propostas, contemplando as seguintes dimensões: ampliação da oferta com aumento de vagas de ingresso; reestruturação acadêmica curricular por meio da reorganização dos cursos de graduação, diversificação das modalidades de graduação, preferencialmente com superação da profissionalização precoce e especializada; renovação pedagógica, mediante a articulação da educação superior com a educação básica, profissional e tecnológica, bem como da atualização de metodologias (e tecnologias) de ensino-aprendizagem e previsão de programas de capacitação pedagógica; mobilidade intra e institucional, promovendo a ampla mobilidade estudantil mediante o aproveitamento de créditos e a circulação de estudantes entre cursos e programas, e entre instituições de educação superior; compromisso social da instituição com políticas de inclusão, programas de assistência estudantil e políticas de extensão universitária; articulação da graduação com a pós-graduação.

Essa proposta não se limita, pois, a um redesenho da arquitetura curricular, mas abrange uma efetiva transformação no processo de formação, com ampliação da base de estudos, possibilitando ampliação de conhecimentos e competências cognitivas, de modo a garantir aos estudantes a condição de formação cidadã, com ênfase nos valores éticos e cívicos que devem orientar a vida numa sociedade justa e democrática ${ }^{(5)}$.

\section{A FORMAÇÃO DOS PROFISSIONAIS DE SAÚDE NA UNIVERSIDADE NOVA}

No campo normativo, UN assegura respaldo para a implementação das mudanças no processo de formação do enfermeiro. Entretanto, a Escola de Enfermagem da Universidade Federal da Bahia (EEUFBA), desde 1998, já construía um processo de mudança para adequar a formação profissional à diversidade e complexidade do mundo contemporâneo.

Com a proposta da UN, essa busca é fortalecida, fundamentando-se no entendimento da necessidade de formar profissionais aptos a aprender a aprender e comprometidos com o enfrentamento dos graves problemas da nossa sociedade. A fundamentação teórica desse entendimento respalda-se na necessidade de formar sujeitos envolvidos na prática pedagógica para aprender a pensar, pensar a realidade, pensar o novo, reinventar o pensar e pensar e reinventar o futuro (aprender a conhecer); saber trabalhar coletivamente, ter iniciativa, ter intuição, saber comunicar-se e saber resolver conflitos (aprender a fazer); compreender o outro, ter prazer no esforço comum e participar em projetos de cooperação (aprender a viver junto); buscar o desenvolvimento integral da pessoa através de inteligência, sensibilidade, ética, responsabilidade, espiritualidade, pensamento autônomo e crítico, imaginação, criatividade e iniciativa (aprender a ser) ${ }^{(7)}$.

Frente à proposta de UM, os contornos do processo de formação dos profissionais de saúde e, mais especificamen- te, dos enfermeiros, deverão contemplar a realidade concreta na qual esse processo se insere, possibilitando ao futuro egresso a capacidade de enfrentar as exigências do mundo do trabalho no Sistema Único de Saúde (SUS), por meio da mobilização de conhecimentos, competências e habilidades gerais e específicas, atendendo aos novos paradigmas da contemporaneidade na produção de conhecimentos e na construção das práticas em saúde/enfermagem.

Nesse paradigma, o processo de formação de profissionais de saúde/enfermagem deve pautar-se no desenvolvimento de ações acadêmicas, multi e interdisciplinares, com base humanista, ética e com capacidade crítica, na perspectiva da integralidade do cuidado, o que pressupõe a formação de profissionais capazes de enfrentar os problemas complexos que se apresentam na sociedade contemporânea, mais especificamente, na área da saúde.

Compreende-se, portanto, que a reestruturação acadêmica no processo de formação de profissionais de saúde/ enfermagem, fruto da mudança paradigmática na contemporaneidade, envolve princípios, a saber:

- reconhecimento da multidimensionalidade da prática profissional (técnica/científica, ética, social, política) como forma de superar o pensar simplificado e fragmentado da realidade;

- percepção da interdisciplinaridade como forma de admitir a ótica pluralista das concepções de ensino, integrando diferentes campos do conhecimento e possibilitando uma visão global da realidade;

- estímulo ao raciocínio clínico ampliado, tendo em vista a integralidade da atenção à saúde e a rede progressiva de cuidados em saúde/enfermagem;

- fomento à indissociabilidade entre as bases biológicas e sociais da atenção à saúde/enfermagem;

- valorização da articulação teoria e prática, contemplando a articulação da pesquisa com o ensino e a extensão, como forma de estabelecer o questionamento reconstrutivo da vida;

- desenvolvimento de habilidades para produção de conhecimento próprio, inovador, assegurando uma assistência de qualidade;

- diversificação de cenários de atenção à saúde;

- utilização de metodologias ativas de ensino-aprendizagem, saindo do pólo do ensino para o da aprendizagem e da centralidade do professor para a centralidade do aluno como sujeito e cidadão;

- adoção da flexibilidade curricular com a incorporação de medidas que se contraponham à rigidez dos pré-requisitos e dos conteúdos obrigatórios. 
Assume-se a transversalidade dos conteúdos trabalhados pelos campos de conhecimento disciplinar, articulandose os conteúdos teórico-práticos, em função das demandas trazidas pelos problemas concretos da realidade e das competências a serem desenvolvidas, numa seqüência orientada pelo grau de autonomia no processo de cuidar.

Assim, a opção colocada para dar conta dos princípios pedagógicos e do perfil esperado para os profissionais de saúde/enfermagem será a de romper com a rigidez das disciplinas, dos pré-requisitos e dos conteúdos obrigatórios (na maioria das vezes desconectados e distantes dos problemas e necessidades colocados pela realidade social), para a construção de um projeto acadêmico em que o eixo da formação passa a ser a prática/trabalho/cuidado voltado para os processos da vida e da saúde dos indivíduos.

Com essa reestruturação acadêmica, espera-se o desenvolvimento de competências gerais, interpessoais e cognitivas, assim como competências específicas relacionadas ao mundo do trabalho no SUS. Para isso, serão necessárias amplas discussões, mobilizando docentes, discentes e profissionais dos cenários da prática, buscando ampliar os espaços de diálogo, interlocução e ação conjunta com os sujeitos coletivos para a construção de uma prática inovadora, que se dará por meio de uma prática social e politicamente responsável ${ }^{(8)}$. Assim, não se pode perder de vista a missão social do processo de formação de profissionais de saúde/enfermagem, agregada à excelência acadêmica como instrumento de produção de saberes e prática efetivamente interdisciplinares.

\section{CONSIDERAÇÕES FINAIS}

A nova proposta de formação de profissionais de saúde/ enfermagem representa, pois, uma alternativa avançada de estudos superiores que permitirão reunir um conjunto de características que hoje vêm sendo requeridas para a formação universitária profissional e cidadã na área da saúde. Representa ainda uma proposta de formação pautada na articulação de conceitos, percepções para a produção de saberes sobres práticas de ensino pautadas na Integralidade. Representa, ademais, a necessidade de se assumir uma postura crítica e criativa que se efetiva entre educação em saúde e trabalho em saúde, ousando uma contemporaneidade das práticas.

\section{REFERÊNCIAS}

1. Chauí M. Escritos sobre universidade. São Paulo: Ed. UNESP; 2001.

2. Universidade Federal da Bahia. Plano de Expansão e Reestruturação da Arquitetura Curricular da Universidade Federal da Bahia. Versão n. 3.1 de 30/07/2007. Salvador; 2007.

3. Ceccim RB, Feuerwerker LCM. Mudança na graduação das profissões de saúde sob o eixo da integralidade. Cad Saúde Pública. 2004;20(5):1400-10.

4. Pinheiro R, Ceccim RB, Mattos RA. Ensinar saúde: a integralidade e o SUS nos cursos de graduação na área de saúde. Rio de Janeiro: IMS/UERJ/ABRASCO; 2005.
Tal inovação requer, portanto, a promoção da interface entre saúde, educação e trabalho, sob a orientação estrutural do SUS, da ética e da cidadania, não se limitando a questões técnicas, relativas à reestruturação da arquitetura acadêmica e de conteúdos de ensino, procedimentos didáticos e técnicas pedagógicas. Ela pauta-se, fundamentalmente, na adoção de um referencial teórico-pedagógico que sustente uma aprendizagem significativa, transformadora e adequada às demandas sociais e profissionais que se apresentam na contemporaneidade.

Nesse sentido, torna-se de fundamental importância o aprofundamento das discussões e de tornar claro para a comunidade universitária que o desenvolvimento de habilidades passa pela necessidade de desenvolver a competência de trabalhar a parte tácita do conhecimento, num processo formativo de verdadeiros cidadãos, capazes de responder aos constantes desafios impostos pela sociedade e, mais especificamente, pelo setor saúde. Passa, pois, pelas oportunidades de reflexão sobre o trabalho/fazer pedagógico na saúde/enfermagem.

Para concluir, é necessário explicitar que este estudo não pretende indicar caminhos a serem percorridos pelas instituições/escolas/cursos para alcançarem as transformações necessárias. Tampouco constitui numa fórmula padronizada, pois modelos ideais servem muito mais à reprodução de referenciais técnico-científicos acumulados pelos docentes em suas respectivas áreas, do que à construção singular do conhecimento. Ademais, não se pretende constituir uma proposta que tudo viria a resolver, pois, nesse caso, estaria se desprezando a complexidade do atuar em saúde e a necessária multirreferencialidade desse agir. Este documento, na verdade, indica a superação das abordagens tradicionais e a necessidade de mudar paradigmas, fazer rupturas com práticas e crenças que nos impedem de fazer mudanças e enfrentar desafios que se apresentam frente às novas exigências em relação ao perfil dos profissionais, às novas modalidades de organização do mundo do trabalho, aos desafios da transdisciplinaridade na produção do conhecimento e à necessidade da universidade resgatar seu papel social e cultural.

5. Almeida Filho N. Universidade Nova: textos críticos e esperançosos. Brasília: Ed. Universidade de Brasília; Salvador: EDUFBA; 2007.

6. Ribeiro RJ. A universidade e a vida atual. Rio de Janeiro: Campus; 2003.

7. Delors J. Educação: um tesouro a descobrir. Lisboa: UNESCO/ ASA; 1996.

8. Fernandes JD, Xavier IM, Ceribelli MI, Bianco MHC, Maeda D, Rodrigues MV. Diretrizes curriculares e estratégias para implantação de uma nova proposta pedagógica. Rev Esc Enferm USP. 2005;39(4):443-9. 